\title{
Optical spectroscopy and tomography of oxygen delivery: From macro to micro and back (Presentation Video)
}

David Boas

David Boas, "Optical spectroscopy and tomography of oxygen delivery: From macro to micro and back (Presentation Video)," Proc. SPIE 8934, Optical Coherence Tomography and Coherence Domain Optical Methods in Biomedicine XVIII, 89342F (22 July 2014); doi: 10.1117/12.2064187

SPIE. Event: SPIE BiOS, 2014, San Francisco, California, United States 


\section{Optical spectroscopy and tomography of oxygen delivery: From macro to micro and back (Presentation Video)}

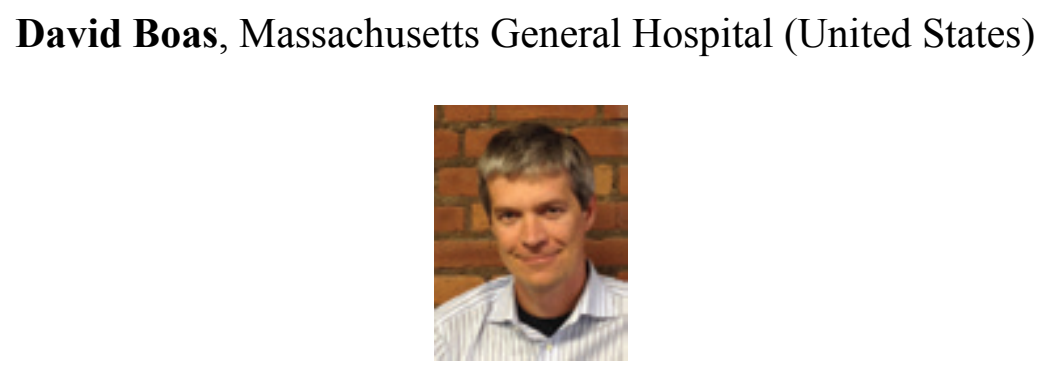

BIOS 2014 Hot Topics Presentation

SPIE member David Boas (Massachusetts General Hospital) discusses techniques for understanding oxygen delivery through the vascular network, in "Optical Spectroscopy and Tomography of Oxygen Delivery: From Macro to Micro and Back."

The use of microscopy coupled with modeling techniques to study the heterogeneous and complex oxygen delivery network and blood flow pattern in the vascular network is detailed.

View presentation video on SPIE's Digital Library: http://dx.doi.org/10.1117/12.2064187 